\title{
INDUSTRIAL APPLICATION OF ATOMIC ENERGY
}

$\mathrm{O}^{\mathrm{s}}$ NE session of the recent meeting at Birmingham of the British Association, held in the Great Hall of the University, was devoted to an account of industrial applications of atomic energy. The session was opened with a paper by Sir John Cockcroft on the problems and prospects of nuclear power development. The paper covered much of the same ground as the discussions in the World Power Conference; but more information was given about the development work proceeding at the Atomic Energy Research Establishment, Harwell. One of the advantages of the second Harwell pile, the B.E.P.O., is that it can be used at the same time for experiments in nuclear physics, solid-state physics, radiation chemistry and nuclear engineering development. One of the most important problems in nuclear power development is to be able to transfer the heat developed in the uranium fuel elements, safely and efficiently, to a conventional power unit, whether it be a steam boiler followed by a turbo-generator station, or in the long run, perhaps, a gas turbine.

The difficulties arise, Sir John pointed out, from the intense radioactivity developed in the fuel elements, which must not be allowed to leak into the heat transfer fluid, the reactive character of the uranium metal--which oxidizes only too readily, given the opportunity-and the effects of neutron bombardment on the mechanical stability of the fuel elements. The uranium fuel elements have to be 'canned' with a metal of low neutron absorption to overcome these difficulties, and the welds of the can must remain free from pinholes during the long working life of the fuel elements. The B.E.P.O. contains 16,000 fuel elements, and during its two years of operation the working temperature and, with it, the power-level, has been steadily raised, while fuel elements are withdrawn at intervals and examined by X-rays to study any incipient troubles. Metallurgical development has gone along with this, and improved fuel elements have been developed which will allow substantially higher temperatures-of the order of $300^{\circ}$ C.- to be reached; and with this the operating power-level should be increased to about 10,000 kilowatts. In order to develop power efficiently, it would be desirable to operate at boiler temperatures similar to those now used in British Electricity Authority power stations, namely, $\mathbf{4 5 5}^{\circ} \mathrm{C}$.; work is therefore proceeding on the metallurgy of beryllium and zirconium, which are promising can. ning materials for these higher temperatures. The metallurgy of these elements is in an early stage of development, so that some time may be required for the necessary development programme. It will be possible to use the B.E.P.O. to test these high-temperature fuel elements as they come from the laboratories of the Harwell metallurgy division.

Another important problem is the stability of constructional materials and moderators used in the power reactors. Mr. T. M. Fry gave an account of the effects of neutron bombardment on the physical properties of several substances of interest to pure physics. Similar studies are proceeding on the technologically important materials as part of a co-operative programme with the Chalk River Atomic Energy Establishment. The high flux of the
Chalk River pile reduces materially the time required for such investigations.

Three new types of power reactors are under consideration. The first is a development of a reactor of the B.E.P.O. type burning natural uranium as its fuel elements. Reactors of this type are near breeders in that the primary fuel element, uranium-235, is partially replaced by the secondary fuel, plutonium, with fission products as a radioactive ash which acts as a 'poison' to the reaction. The 'burning time' of the fuel elements will depend very much on the degree of such poisoning. A hypothetical reactor containing 200 tons of uranium metal and developing 200 megawatts of heat might have a fuel burningtime of between ten and thirty years before its reactivity fell to unity and the chain reaction ceased. Experience is being gained which will decide this point. The burning-time is obviously important since it determines the fuel requirements of such a system, and with it the fuel and therefore the power costs. Burning times of ten and thirty years would require an annual consumption of about 1,800 and 600 tons of uranium metal respectively to supply the power needs of the United Kingdom alone, and such a system could only be supported if the extraction of uranium from low-grade ores could be carried out at reasonable cost. Experimental work on extraction from low-grade ores is now proceeding at Harwell and at the Chemical Research Laboratory at Tedding. ton.

It will not be possible to decide on the feasibility of nuclear power or to give any good estimate of its costs until pilot power-producers are built and operated. Very rough figures of the capital and fuel costs of a modern British Electricity Authority power station compare not unfavourably with guessed figures of the additional cost of the nuclear boiler and limits of cost of uranium fuel elements, assuming refuelling times of ten and thirty years respectively. These figures do no more than show that nuclear power costs will be likely to be of the same general order as conventional power costs, and that it is worth while to proceed with development work to determine these costs more accurately. Pilot plants based on natural uranium fuel elements would be bulky and costly. It is therefore desirable to reduce the scale of pilot power-producers by using enriched uranium fuel elements ; feasibility and design studies of such a reactor are now being carried out at Harwell in collaboration with an industrial organisation. Construction will probably take three to five years after approval is given to the project.

Design studies are also being carried out on an experimental breeder reactor, one of which is already under construction in the United States.

This experimental and development programme is likely to occupy the next decade. If the development work is successful, nuclear power would be likely to start in specialized applications where fuel costs are less important, and then to spread gradually to more conventional power stations. British fuel reserves have been estimated as lasting from 200 to 300 years by Dr. A. Parker, director of the Fuel Research Station, Greenwich ; power consumption is increasing by 10 per cent a year and there is increasing competition with the chemical engineering industry for 
fuel. New power sources are therefore of considerable long-term importance, though other potentialities should be pursued in addition to nuclear power.

Dr. H. Seligman spoke next on the immediate benefits which atomic piles are providing, in particular the industrial use of radioactive isotopes. The expansion of radioisotope production at Harwell has been so rapid that practically all the surplus neutron flux in B.E.P.O. is now used, and a limit to the supply of radioactive materials requiring high fluxsuch as radiographic sources-may very soon be reached, unless measures are taken to increase the available neutrons.

A number of industrial applications were described. The use of thickness gauges using a $\beta$-emitter as a source on one side of a continually produced strip and a detector on the other is extending from the paper, plastic and cardboard mills to steel mills, and for this purpose the fission product strontium-90, which emits an energetic $\beta$-ray, is required. For this purpose facilities for the separation of substantial quantities of fission products are being installed at Harwell. At present only pilot-scale facilities are operating.

'Static eliminators' containing thallium-204, for the dissipation of undesirable electric charges, are being made experimentally at Harwell and lent to firms for trial. It is thought that in six months or so static eliminators will be available commercially to satisfy all industrial demands.

Other applications make use of the extremely sensitive methods of detecting radioactive elements. For example, radioactive sodium is being used to trace a suspected leak from a lake containing fifty million gallons of water to coal pits. Radioactive bromine contained in an organic compound has been used to check the ventilation system of a factory; radioactive sodium has been used to check the efficiency of mixing of one gram of a vitamin in five tons of cattle food.

Radioactive cobalt has been used in several pipeline operations. At the Gasification Research Station the intersection of two borings in a coal seam was facilitated by inserting a 500 -millicurie cobalt source in one seam and a detector in the other. The clearing of long pipe-lines is assisted by making the scrubber radioactive, so that its position can be determined in case of blockages.

These are a few representative applications out of a hundred or so which the Atomic Energy Research Establishment has developed or helped to develop for industry. It is believed that much more use of isotopes could be made in industry, and it is hoped to start at Harwell in the early part of 1951 a training school in their applications.

Mr. W. S. Eastwood described the application of isotopes to radiography in industry. The Harwell pile is now producing $\gamma$-emitting sources having conveniently long half-lives-60 days to 5 yearsand a wide range of $\gamma$-ray energies, so that the energy most suitable for the job can be chosen. The isotopes in most demand are radiocobalt (half-life $5 \cdot 3$ years; energy $1 \cdot 1,1 \cdot 3 \mathrm{MeV}$.$) ; radioiridium (half-life 70$ days; energy $0.30,0.47,0.60 \mathrm{MeV}$.) and radiotantalum (half-life 120 days; energy $0.15,0.22$, $1 \cdot 13,1 \cdot 22 \mathrm{MeV}$.). In the future, sources of europium (half-life 5 years; energy $0.12,0.34,0.41,1.2$ $\mathrm{MeV}$.) ; cerium (half-life 275 days; energy $1 \cdot 25$, $0 \cdot 22 \mathrm{MeV}$.) will be available.

One of the advantages of these radioactive sources is that they are comparatively easily and safely handled, and that they can be reactivated after decay by returning to the pile. They are standardized in the form of cylinders having a diameter equal to length with dimensions of $6 \mathrm{~mm} ., 4 \mathrm{~mm}$. and $2 \mathrm{~mm}$. Specific activities can be as high as several curies per gram. The use of these isotopes is extending steadily in industry, both in Great Britain and abroad. The number which can be produced will be limited by the surplus neutrons available in B.E.P.O.

\section{CLIMATIC LIMITS OF VEGETATION}

$T$ HE climatic limits of the major types of vegetation and of plant species, especially those of economic importance, are a topic of great practical as well as theoretical interest. In Great Britain it has received comparatively little attention, doubtless because the range of climate in the British Isles is relatively insignificant and the effects of other ecological factors more striking. The subject was therefore appropriate for a joint meeting of Sections $K$ (Botany) and $K^{*}$ (Forestry) of the British Associa. tion held at Birmingham on September 1.

Prof. P. W. Richards (University College, Bangor) opened with a discussion of the climatic limits of the Tropical Rain Forest. The optimum conditions for its development are found in areas such as the Malay Peninsula, where the climate is characterized by high and evenly distributed rainfall. Towards the periphery of the Tropical Rain Forest (using the term in the broad sense originally proposed by Schimper), the rainfall becomes more seasonal in its distribution, until a limit is reached where evergreen forest gives way to deciduous forest or savanna. This increasingly uneven distribution of rainfall is accompanied by an increase in the seasonal variation of temperature, but there is little reason for believing that temperature plays much part in determining the limits of the rain forest in lowland country. The altitudinal limit on mountains seems to be partly due to temperature, though even there other factors, such as reduced light intensity due to cloudiness, are probably important. In general, the evidence points to moisture conditions as playing the chief part in limiting the rain forest, which is thus controlled by factors affecting the ability of the vegetation to maintain its water balance rather than by factors affecting photosynthesis or the length of the growing season.

If this is so, we should not expect a very close correlation between the rain forest limits and any simple expression of climate, since factors such as soil texture, drainage, etc., affecting water uptake, are likely to be as important as factors affecting the rate and amount of water lost in transpiration.

The complexity of the factors controlling the boundary of the rain forest is well illustrated in Africa. In the Central Congo basin, Bernard ${ }^{1}$ found a satisfactory correlation between the distribution of typical rain forest, peripheral transitional areas and savanna with Köppen's $A f, A m$ and $A w$ climates respectively; but in West Africa conditions are not so simple. In Nigeria the boundaries between 'True Rain Forest' and 'Mixed Deciduous Forest' and between the latter and the savanna seem to be correlated not, as might be expected, with the length of the dry season, but with the total annual rainfall. As the annual total depends largely on the amount of rain falling in the wet months, which is far in 